\title{
Pinane-Type Tridentate Reagents for Enantioselective Reactions: Reduction of Ketones and Addition of Diethylzinc to Aldehydes
}

\author{
Yie-J ia Cherng, ${ }^{\dagger} \mathrm{J}$ im-Min Fang, ${ }^{*, \dagger}$ and Ta-J ung $\mathrm{Lu}^{*,+}$ \\ Department of Chemistry, National Taiwan University, Taipei 106, Taiwan, Republic of China, and \\ Department of Chemistry, National Chung-Hsing University, Taichung 402, Taiwan, Republic of China
}

Received December 8, 1998

\begin{abstract}
The reduction of aryl and alkenyl methyl ketones using lithium aluminum hydride modified with $(1 \mathrm{R}, 2 \mathrm{~S}, 3 \mathrm{~S}, 5 \mathrm{R})-(+)-10$-anilino-3-ethoxy-2-hydroxypinane (10b) afforded chiral secondary al cohols in $83-96 \%$ chemical yields and $50-91 \%$ ee with dominance of $R$ enantiomers. The reduction of acetophenone in the presence of lithium iodide gave the alcohol product with higher ee. On the other hand, the addition reaction of diethylzinc to benzaldehyde using the pinane-based diols 5-9 as promoters gave 1-phenylpropanol in favor of the S enantiomer up to $88 \%$ ee. Using the pinanebased alcohols $10 \mathbf{a}-\mathbf{e}$ as promoters, the R enantiomer was obtained as the major product. The addition reactions of diethylzinc to various substituted benzal dehydes, employing the diol ligands 5c and 8e, afforded predominantly the corresponding (S)-alcohols. The chiral modifiers 5-10 were prepared from (1R)-(-)-myrtenol and were readily recovered (>90\%) after the asymmetric reactions. In this study, LAH reduction and $\mathrm{Et}_{2} \mathrm{Zn}$ addition are complementary methods for the preparation of optically active secondary al cohols. The ligand 10-butylanilino-2,3-dihydroxypinane 5c promoted the $\mathrm{Et}_{2} \mathrm{Zn}$ additions effectively, whereas the modifier 10-anilino-3-ethoxy-2-hydroxypinane 10b induced the LAH reductions in a highly enantioselective manner.
\end{abstract}

\section{Introduction}

Enantiomerically pure chiral secondary alcohols are important starting materials for the total synthesis of natural products. ${ }^{1}$ Asymmetric reduction of ketones $^{2}$ and nucleophilic addition to aldehydes ${ }^{3}$ are two general methods for the preparation of optically active secondary alcohols. In this paper, we report the use of pinane-type tridentates 5-12 (Figure 1) as the chiral modifiers of lithium aluminumhydride (LAH) reductions and diethylzinc additions. Asymmetric LAH reduction ${ }^{2}$ and $\mathrm{Et}_{2} \mathrm{Zn}$ addition $^{3}$ have been advanced to achieve high efficiency and remarkable enantioselectivity. Pinanes and their derivatives are economic and readily available compounds; pinane-derived boranes, ${ }^{4}$ such as Alpine-Borane

† National Taiwan University. Current address of YJ C: Chung-Tai Institute of Health Science and Technology, Taichung, Taiwan.

$¥$ National Chung-Hsing University.

(1) Application of chiral al cohols to the synthesis of leukotrienes and alkaloids: (a) Sato, F.; K obayashi, Y. Synlett 1992, 849. (b) Grigg, R.; Santhakumar, V.; Sridharan, V.; Thornton-Pett, M.; Bridge, A. W. Tetrahedron 1993, 49, 5177. (c) I wata, C.; Takemoto, Y. Chem. Commun. 1996, 2497.

(2) Reviews of asymmetric reduction of ketones: (a) Nishizawa, M.; Noyori, R. in Comprehensive Organic Synthesis; Trost, B. M., Fleming, I., Eds.; Pergamon Press: Oxford, 1991; Vol. 8, pp 159-182. (b) Singh, V. K. Synthesis 1992, 605. (c) Parratt, J . S.; Cripps, M. C.; Faulconbridge, S. J .; Holt, K. E.; Rippe, C. L.; Savage, S. P.; Taylor, S. J. C. Annu. Rep. Prog. Chem., Sect. B: Org. Chem. 1997, 93, 291. (d) Pereira, R. D. Crit. Rev. Biotechnol. 1998, 18, 25. Examples of asymmetric LAH reductions: (e) Landor, S. R.; Miller, B. J .; Tatchell, A. R. J . Chem. Soc. C 1966, 2280. (f) Baggett, N.; Stribblehill, P.J . Chem. Soc., Perkin Trans. 1 1977, 1123. (g) Noyori, R.; Tomino, I.; Nishizawa, M. J . Am. Chem. Soc. 1979, 101, 5843.

(3) Reviews of asymmetric $\mathrm{Et}_{2} \mathrm{Zn}$ additions: (a) Noyori, R.; Kitamura, M. Angew. Chem., Int. Ed. Engl. 1991, 30, 49. (b) Soai, K.; Niwa, S. Chem. Rev. 1992, 92, 833. (c) J iang, Y.; Qin, Y.; Huang, Z. Hecheng Huaxue 1993, 1, 1. (d) Berrisford, D. J .; Bolm, C. Angew. Chem., Int. Ed. Engl. 1995, 34, 1717. (e) Mikami, K.; Terada, M. Kagaku to Kogyo (Osaka) 1997, 71, 249.

(4) (a) Midland, M. M.; McDowell, D. C.; Hatch, R. L.; Tramontano, A. J . Am. Chem. Soc. 1980, 102, 867. (b) Brown, H. C.; Ramachandran, P. V. Acc. Chem. Res. 1992, 25, 16. (c) Deloux, L.; Srebnik, M. Chem. Rev. 1993, 93, 763. and $(\mathrm{I} \mathrm{pc})_{2} \mathrm{BCl}$, have been successfully utilized in asymmetric reduction of ketones. Unlike bidentate chiral ligands, the tridentate chiral ligands are not extensively studied. We envisaged that $\mathrm{LAH}$ and $\mathrm{Et}_{2} \mathrm{Zn}$ can be modified by the tridentate ligands $\mathbf{5}-\mathbf{1 2}$ to form chiral reagents with rigid structure, which may exert distinct stereochemical bias to convey asymmetric induction. We report herein the study in this aspect. ${ }^{5}$

\section{Results and Discussion}

Preparation of pinane-type tridentates 5-12 was straightforward (Scheme 1). (1R)-(-)-Myrtenol (1) was reacted with $\mathrm{PBr}_{3}$ to give (1R)-(-)-myrtenyl bromide (2) in $85 \%$ yield. The substitution reaction of $\mathbf{2}$ was easily carried out by treatment with a series of amines and alcohols, giving $\mathbf{3}$ and $\mathbf{4}$, which were subsequently converted to diols 5-9 by the known procedure using $\mathrm{OsO}_{4}-\mathrm{Me}_{3} \mathrm{NO}$ as the oxidizing agents. Alternatively, compounds 4 could be prepared by alkylation of (1R)(-)-myrtenol with alkyl bromides. Sel ective alkylation of the secondary hydroxyl group of the diols 5-9 furnished the desired modifiers $\mathbf{1 0 - 1 2}$ in respectable yields.

To determine the optical purity of the prepared ligands, a 3,5-dinitrobenzoate derivative $\mathbf{1 3}$ was synthesized from 10b for HPLC analysis (Scheme 2). A racemic mixture of $\beta$-pinene underwent photooxidation, followed by $\mathrm{NaBH}_{4}$ reduction of the resulting hydroperoxide, to afford $( \pm)$ myrtenol. By a procedure similar to that described in Scheme 1, $( \pm)$-myrtenol was transformed into $( \pm)$-10b via dihydroxylation and selective ethylation of the resulting diol. Treatment of $( \pm)$-10b with 3,5-dinitrobenzoyl chloride in the presence of $\mathrm{Et}_{3} \mathrm{~N}$ yielded a racemic ester $( \pm)$ 13, of which two enantiomers were separable on a

(5) Our earlier reports on asymmetric LAH reductions: (a) Lu, T.J .; Liu, S.-W. J . Chin. Chem. Soc. 1994, 41, 205. (b) Lu, T.-J .; Liu, S.-W. J . Chin. Chem. Soc. 1994, 41, 467. (c) Cherng, Y.-J .; Fang, J .M.; Lu, T.-J . Tetrahedron: Asymmetry 1995, 6, 89. 

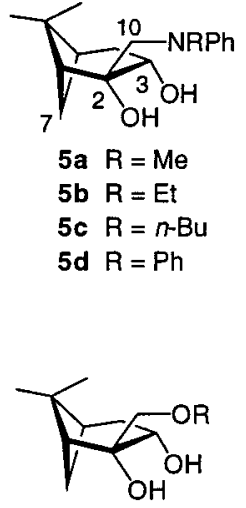

7a $\mathrm{R}=\mathrm{Me}$ $7 \mathrm{~b} \mathrm{R}=n-\mathrm{C}_{8} \mathrm{H}_{17}$ 7c $\mathrm{R}=\mathrm{CH}(n-\mathrm{Bu})_{2}$ 7d $\mathrm{R}=\mathrm{CMe}_{2} \mathrm{CHMe}_{2}$ 7e $\mathrm{R}=\mathrm{CH}_{2} \mathrm{CH}_{2} \mathrm{Ph}$

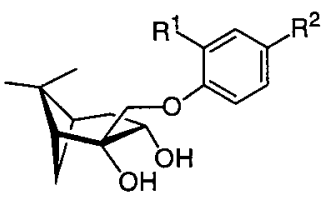

9a $\mathrm{R}^{1}=i-\mathrm{Pr}, \mathrm{R}^{2}=\mathrm{H}$ 9b $R^{t}=t-B u, R^{2}=M e$

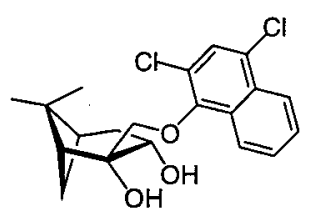

9d

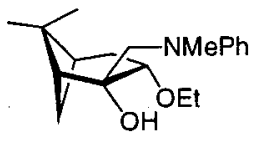

11

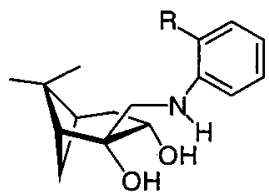

6a $\mathrm{R}=\mathrm{H}$

6b $\mathrm{R}=\mathrm{Me}$

6c $\mathrm{R}=n-\mathrm{Pr}$

6d $\mathrm{R}=j \mathrm{Pr}$

6e $R=t-B u$

6f $\mathrm{R}=\mathrm{OMe}$

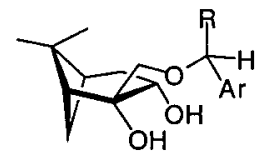

8a $\mathrm{R}=\mathrm{H}, \mathrm{Ar}=\mathrm{Ph}$

8b $\mathrm{R}=\mathrm{H}, \mathrm{Ar}=\mathrm{C}_{6} \mathrm{H}_{4}-\mathrm{O}-\mathrm{OMe}$

8c $R=H, A r=2-N a p h t h y l$

8d $\mathrm{R}=\mathrm{Ar}=\mathrm{Ph}$

8e $\mathrm{R}=\mathrm{Pr}, \mathrm{Ar}=\mathrm{Ph}$ (S-form)

8f $\mathrm{R}=\mathrm{Pr}, \mathrm{Ar}=\mathrm{Ph}(R$-form)
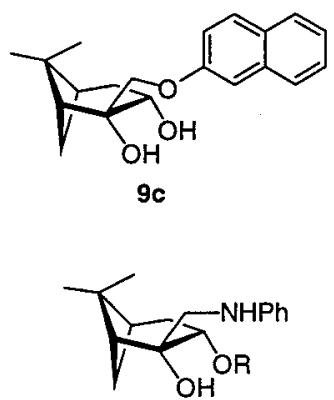

10a $R=M e$

10b $R=E t$

10c $\mathrm{R}=n-\mathrm{Pr}$

$\operatorname{10d} R=n-B u$

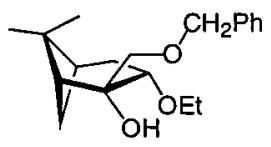

12 10e $\mathrm{R}=\mathrm{CH}_{2} \mathrm{Ph}$

Figure 1. Pinane-type tridentates used in this study.

Chiralcel OD column. An optically enriched sample 10b, $[\alpha]^{25} \mathrm{D}+11.5\left(\mathrm{CHCl}_{3}, \mathrm{C} 1.04\right)$ was similarly prepared from (1R)-(-)-myrtenol and converted to the ester 13, which consisted of two enantiomers in a ratio of 96.9:3.1 as determined by the HPLC analysis. The original sample of (1R)-(-)-myrtenol and the ligand (+)-10b therefrom were thus deduced to have $93.8 \%$ enantiomeric excess (ee).

LAH Reductions. Our preliminary study $5 a, b$ indicated that secondary alcohols can be obtained in moderate optical yields (up to 52\%) in the reduction of prochiral ketones by LAH using pinane-based diol modifiers 5-9. After examination of the Dreiding molecular models of putative transition structures (see Figure 3$)^{6}$ in an attempt to develop more effective modifiers, we envisaged that a C-3 alkoxy group is sterically more demanding than a hydroxyl group and therefore can better dif-

\section{Scheme $1^{\text {a }}$}
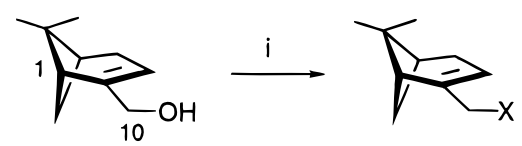

1
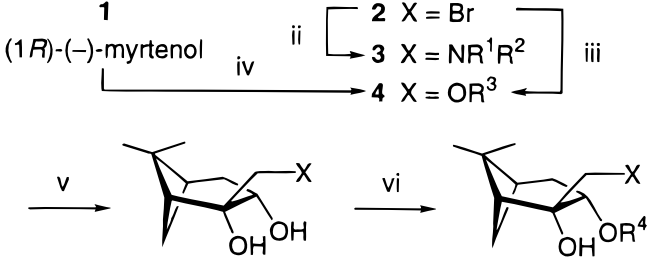

5-6 $X=N R^{1} R^{2}$

7-9 $X=O R^{3}$

$10-11 X=N R^{1} R^{2}$

$12 X=O R^{3}$

a Reagents and conditions: (i) $\mathrm{PBr}_{3}$, pyridine, $\mathrm{PhH}, \mathrm{rt}, 1 \mathrm{~h}, 85 \%$; (ii) $\mathrm{KH}, \mathrm{R}^{1} \mathrm{R}^{2} \mathrm{NH}, \mathrm{THF}, \mathrm{rt}, 3 \mathrm{~h}, 74-85 \%$; (iii) $\mathrm{R}^{3} \mathrm{OH}, \mathrm{KH}, \mathrm{THF}, \mathrm{rt}$, $6 \mathrm{~h}, 65-81 \%$; (iv) $\mathrm{NaH}$ or $\mathrm{KH}, \mathrm{R}^{3} \mathrm{Br}, \mathrm{rt}, 6 \mathrm{~h}, 80-98 \%$; (v) $\mathrm{OsO}_{4}$, $\mathrm{Me}_{3} \mathrm{NO}$, THF/Me2 $\mathrm{CO} / \mathrm{H}_{2} \mathrm{O}$, reflux, 4 days, $50-81 \%$; (vi) $\mathrm{NaH}, \mathrm{R}^{4} \mathrm{Br}$, rt, 24 h, 76-92\%.

\section{Scheme $2^{\mathrm{a}}$}

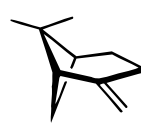

$( \pm)$ - $\beta$-pinene

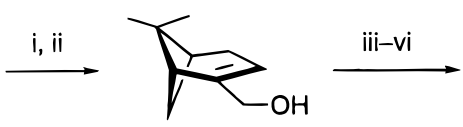

(士)-myrtenol

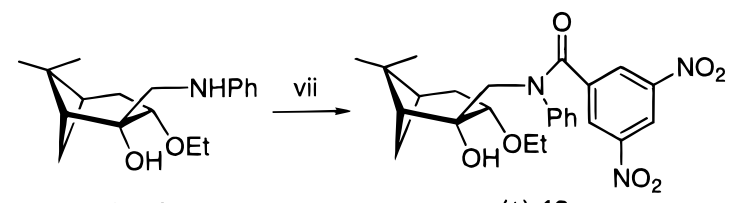

$( \pm)-10 b$

$( \pm)-13$

a Reagents and conditions: (i) $\mathrm{O}_{2}, \mathrm{TPP}, \mathrm{h} v, \mathrm{CHCl}_{3}$; (ii) $\mathrm{NaBH}_{4}$, $\mathrm{MeOH}$; (iii) $\mathrm{PBr}_{3}$, pyridine, $\mathrm{PhH}, \mathrm{rt}, 85 \%$; (iv) $\mathrm{KH}, \mathrm{R}^{1} \mathrm{R}^{2} \mathrm{NH}, \mathrm{THF}$, rt, 85\%; (v) $\mathrm{OsO}_{4}, \mathrm{Me}_{3} \mathrm{NO}$, THF $/ \mathrm{Me}_{2} \mathrm{CO} / \mathrm{H}_{2} \mathrm{O}$, reflux, $50 \%$; (vi) $\mathrm{NaH}$, $\mathrm{EtBr}, 83 \%$; (vii) 3,5-( $\left.\mathrm{NO}_{2}\right)_{2} \mathrm{C}_{6} \mathrm{H}_{3} \mathrm{COCl}, \mathrm{Et}_{3} \mathrm{~N}$.

ferentiate the two reaction faces of the reactant. Thus, rationally designed pinane-based modifiers 10-12, possessing a rigid bicyclic pinane skeleton and an ethoxy substituent at $\mathrm{C}-3$, were prepared. ${ }^{5 \mathrm{C}} \mathrm{The} \mathrm{LAH}$ reduction of acetophenone using modifiers $\mathbf{1 1}$ or $\mathbf{1 2}$, having benzyloxy or N-methylanilino groups at C-10, still resulted in low enantioselectivity (up to $26 \%$ ee). However, remarkable enantiosel ectivity was procured by using the modifier $\mathbf{1 0}$ containing an anilino group at C-10. Table 1 lists the results of asymmetric LAH reductions of acetophenone and 1-acetylnaphthalene using modifiers $10 \mathrm{a}-\mathbf{e}$ with different alkoxy groups at C-3. The reactions were carried out in $\mathrm{Et}_{2} \mathrm{O} / \mathrm{THF}$ (1:10) solution with a ratio of $\mathrm{LAH} /$ modifier/ketone $=2.0: 2.2: 1.0$. The best ee values, $62 \%$ and $80 \%$ for the reactions of acetophenone and 1-acetylnaphthalene, were obtained by using the modifier $\mathbf{1 0 b}$ having an ethoxy group at C-3. Use of 10e having a benzyloxy group at C-3 resulted in an opposite enantiotopic selection, though the ee values were low $(15 \%$ and $3 \%)$.

(6) Anal ogous transition states in asymmetric LAH reductions using aminodiol or diamino alcohol tridentate modifiers have been proposed. (a) Morrison, J . D.; Grandbois, E. R.; Howard, S. I.; Weisman, G. R. Tetrahedron Lett. 1981, 22, 2619. (b) Sato, T.; Goto, Y.; Fujisawa, T. Tetrahedron Lett. 1982, 23, 4111. Similar transition states in the reactions of organolithiums: (c) Mukaiyama, T.; Soai, K.; Sato, T.; Shimizu, H.; Suzuki, K. J . Am. Chem. Soc. 1979, 101, 1455. (d) Corey, E. J .; Hannon, F. J . Tetrahedron Lett. 1987, 28, 5233. (e) Seebach, D. Angew. Chem., Int. Ed. Engl. 1988, 27, 1624. 
Table 1. LAH Reduction of Acetophenone and 1-Acetylnaphthalene Using Modifiers $10 a-e^{a}$

\begin{tabular}{clllll}
\hline entry & \multicolumn{1}{c}{ ketone } & \multicolumn{1}{c}{$\begin{array}{c}\text { modifier, } \\
\mathrm{R}=\end{array}$} & $\begin{array}{c}\text { product } \\
(\text { yield/\%) }\end{array}$ & $\begin{array}{c}\text { eec/ } \\
\%\end{array}$ & configd \\
\hline 1 & acetophenone & $\mathbf{1 0 a}, \mathrm{Me}$ & $\mathbf{1 4 a}(83)$ & 48 & $\mathrm{R}$ \\
2 & acetophenone & $\mathbf{1 0 b}, \mathrm{Et}$ & $\mathbf{1 4 a}(85)$ & 62 & $\mathrm{R}$ \\
3 & acetophenone & $\mathbf{1 0 c}, \mathrm{Pr}$ & $\mathbf{1 4 a}(85)$ & 47 & $\mathrm{R}$ \\
4 & acetophenone & $\mathbf{1 0 d}, \mathrm{Bu}$ & $\mathbf{1 4 a}(86)$ & 46 & $\mathrm{R}$ \\
5 & acetophenone & $\mathbf{1 0 e}, \mathrm{PhCH} 2$ & $\mathbf{1 4 a}(84)$ & 14 & $\mathrm{~S}$ \\
6 & 2-acetylnaphthalene & $\mathbf{1 0 a}, \mathrm{Me}$ & $\mathbf{1 4 i}(84)$ & 55 & $\mathrm{R}$ \\
7 & 2-acetylnaphthalene & $\mathbf{1 0 b}, \mathrm{Et}$ & $\mathbf{1 4 i}(93)$ & 80 & $\mathrm{R}$ \\
8 & 2-acetylnaphthalene & $\mathbf{1 0 c}, \mathrm{Pr}$ & $\mathbf{1 4 i}(87)$ & 62 & $\mathrm{R}$ \\
9 & 2-acetylnaphthalene & $\mathbf{1 0 d}, \mathrm{Bu}$ & $\mathbf{1 4 i}(86)$ & 66 & $\mathrm{R}$ \\
10 & 2-acetylnaphthalene & $\mathbf{1 0 e}, \mathrm{PhCH} 2$ & $\mathbf{1 4 i}(90)$ & 3 & $\mathrm{~S}$
\end{tabular}

a The reaction was conducted in $\mathrm{Et}_{2} \mathrm{O} / \mathrm{THF}(1: 10)$ solution at $-78{ }^{\circ} \mathrm{C}$ for $1 \mathrm{~h}$ with a molar ratio of $\mathrm{LAH} /$ modifier/ketone $=2.0$ : 2.2:1.0. ${ }^{b}$ I solated yields. ${ }^{\mathrm{C}}$ The ee value was determined by HPLC analysis. ${ }^{d}$ The configuration of the major enantiomer was assigned by comparison of the optical rotation with the reported value.

Table 2. Reduction of Methyl Ketones $\mathrm{RCOCH}_{3}$ with $\mathrm{LiAlH}_{4}$ and Chiral Modifier 10ba

\begin{tabular}{clllll}
\hline entry & \multicolumn{1}{c}{$\mathrm{RCOCH}_{3}, \mathrm{R}=$} & $\begin{array}{c}\text { additive } \\
\text { (equiv) }^{\mathrm{b}}\end{array}$ & $\begin{array}{c}\text { product } \\
\text { (yield/\%) }\end{array}$ & $\begin{array}{c}\mathrm{ee} \\
(\%)\end{array}$ & config \\
\hline 1 & $\mathrm{Ph}$ & $\mathrm{Lil}(1)$ & $\mathbf{1 4 a}(85)$ & 62 & $\mathrm{R}$ \\
2 & $\mathrm{Ph}$ & & $\mathbf{1 4 a}(91)$ & 83 & $\mathrm{R}$ \\
3 & o-tolyl & & $\mathbf{1 4 b}(86)$ & 79 & $\mathrm{R}$ \\
4 & 2-bromophenyl & & $\mathbf{1 4 d}(86)$ & 78 & $\mathrm{R}$ \\
5 & 2-chlorophenyl & & $\mathbf{1 4 d}(86)$ & 78 & $\mathrm{R}$ \\
6 & 2-methoxyphenyl & & $\mathbf{1 4 e}(86)$ & 91 & $\mathrm{R}$ \\
7 & 2-nitrophenyl & & $\mathbf{1 4 f}(85)$ & $72^{\mathrm{d}}$ & $\mathrm{R}$ \\
8 & 2,4-dimethylphenyl & & $\mathbf{1 4 g}(87)$ & 74 & $\mathrm{R}$ \\
9 & 2,5-dimethoxyphenyl & & $\mathbf{1 4 h}(91)$ & 91 & $\mathrm{R}$ \\
10 & 1-naphthyl & Lil (1) & $\mathbf{1 4 i}(93)$ & 80 & $\mathrm{R}$ \\
11 & 1-naphthyl & $\mathbf{1 4 i}(92)$ & 84 & $\mathrm{R}$ \\
12 & 1-naphthyl & & $\mathbf{1 4 i}(85)$ & 66 & $\mathrm{R}$ \\
13 & 2-naphthyl & $\mathbf{1 4 j}(96)$ & 50 & $\mathrm{R}$ \\
14 & 2-phenanthyl & & $\mathbf{1 4 k}(94)$ & 87 & \\
15 & 2-fluorenyl & $\mathbf{1 4 l}(95)$ & 81 & \\
16 & 2-furyl & & $\mathbf{1 5}(88)$ & 52 & $\mathrm{R}$ \\
17 & 2-thienyl & & $\mathbf{1 6 a}(90)$ & 83 & $\mathrm{R}$ \\
18 & 2-(3-methylthienyl) & & $\mathbf{1 6 b}(92)$ & 54 & \\
19 & 2-(5-chlorothienyl) & & $\mathbf{1 6 c}(92)$ & 61 & \\
20 & 2-(5-bromothienyl) & & $\mathbf{1 6 d}(94)$ & 63 & \\
21 & PhCH=CH & & $\mathbf{1 7}(93)$ & 50 & $\mathrm{R}$ \\
22 & PhCH=CH & Lil (1) & $\mathbf{1 7}(91)$ & 52 & $\mathrm{R}$ \\
23 & 1-cyclohexenyl & & $\mathbf{1 8}(89)$ & 74 d & $\mathrm{R}$
\end{tabular}

a Refer to the footnote of Table 1 for reaction conditions, isolated yields, eevalues, optical yields, and absolute configuration of major enantiomers. b Based on the amount of respective ketone. c The alcohol product was treated with phenyl isocyanide to give the corresponding carbamate, of which the ee value was determined by HPLC analysis. ${ }^{d}$ The alcohol product was treated with 3,5dinitrobenzoyl chloride to give the corresponding ester, of which the ee value was determined by HPLC analysis.

Several mono- and disubstituted acetophenones were reduced by $\mathrm{LAH} / \mathbf{1 0 b}$ (Table 2 ) to afford the corresponding phenylethanols $\mathbf{1 4 a}-\mathbf{h}$ (Figure 2) in favor of the $\mathrm{R}$ configuration al cohols (62-91\% ee). The chiral reducing agent was prepared in situ by mixing a standardized $\mathrm{Et}_{2} \mathrm{O}$ stock solution of $\mathrm{LAH}$ with modifier $\mathbf{1 0 b}$ at room temperature for $1 \mathrm{~h}$. THF solutions of prochiral ketones were then added at $-78{ }^{\circ} \mathrm{C}$ and stirred for another $1 \mathrm{~h}$ to furnish the corresponding secondary alcohols in 83$96 \%$ chemical yields. The nitro group did not interfere with the reduction of methyl 2-nitrophenyl ketone (Table 2 , entry 7 ), giving $85 \%$ of the desired alcohol. The chiral modifier 10b was recovered nearly quantitatively (>96\%) from the reaction mixture by silica gel chromatography. Among the examined examples, the reduction of 2 methoxyacetophenone and $2^{\prime}, 5^{\prime}$-dimethoxyacetophenone

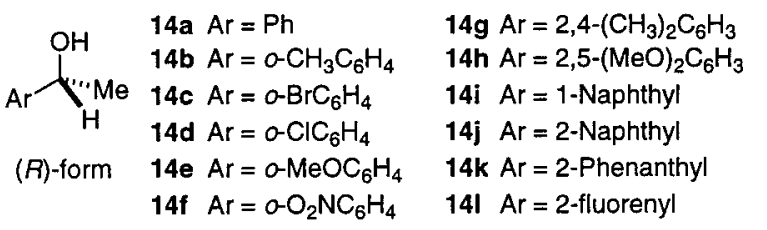

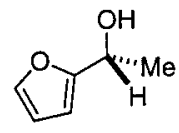

$15(R)$-form

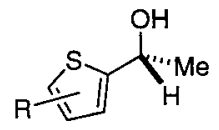

(R)-form $\begin{array}{ll}16 a & R=H \\ 16 b & R=3-C_{3} \\ 16 c & R=5-C l \\ 16 d & R=5-B r\end{array}$<smiles>C[C@H](O)/C=C/c1ccccc1</smiles>

$17(R)$-form

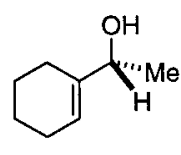

$18(R)$-form<smiles>CCC(O)c1ccccc1</smiles>

(S)-form

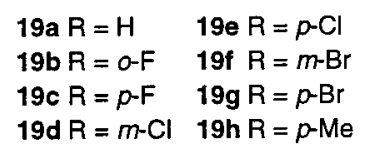

Figure 2. In this study, the asymmetric $\mathrm{LAH}$ reduction gave predominantly $(R)$-alcohols 14-18, whereas the asymmetric $\mathrm{Et}_{2} \mathrm{Zn}$ addition gave predominantly (S)-alcohols $\mathbf{1 9}$.

(Table 2, entries 6 and 9) gave the highest optical yield (97\%) by calculation based on the maximum optical purity (93.8\%) of the modifier $\mathbf{1 0 b}$.

A wide range of aromatic and alkenyl methyl ketones can be reduced by LAH in the presence of modifier $\mathbf{1 0 b}$ to give chiral secondary alcohols in synthetically useful yields and enantioselectivities. 1-Acetylnaphthalene, 2-acetyl naphthal ene, 2-acetyl phenanthrene, and 2-acetylfluorene were reduced to give $80,50,87$, and $81 \%$ ee, respectively. Heterocyclic compounds, such as 2-acetylfuran and 2-acetylthiophenes (Table 2, entries 16-20), were similarly reduced to achieve $52-83 \%$ ee. The reductions of 4-phenyl-3-buten-2-one and cyclohexenyl methyl ketone also produced the corresponding allylic alcohols with predominance of $\mathrm{R}$ enantiomers. No 1,4reduction products were observed in such instances.

A 1:10 mixture of $\mathrm{Et}_{2} \mathrm{O} / \mathrm{THF}$ appeared to be the solvent of choice for the asymmetric $\mathrm{LAH}$ reduction. When the reduction of 1-acetylnaphthalene was conducted in $\mathrm{Et}_{2} \mathrm{O}$ or $\mathrm{Et}_{2} \mathrm{O} / \mathrm{THF}(1: 1)$ solution, the enantioselectivity dropped dramatically, giving 14i with $31-35 \%$ ee. As the addition of HMPA or lithium iodide is known to affect the enantioselectivities in certain reactions (such as alkylation reactions of enolates or allylmetals), ${ }^{7}$ we also examined their effects in the LAH reductions. Our results indicated that the enantioselectivity of the al cohol products was increased in some instances by addition of Lil (Table 2, entries 2, 11, and 22). On the other hand, the enantioselectivity decreased in the reduction of 1-acetylnaphthalene in the presence of the cosolvent HMPA (Table 2, entry 12).

(7) (a) Seebach, D. Angew. Chem., Int. Ed. Engl. 1988, 27, 1624. (b) Chang, C.-J .; Fang, J.-M.; Liao, L.-F. J . Org. Chem. 1993, 58, 1754 and the references therein. 


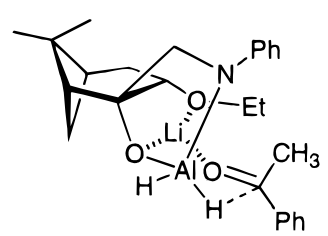

A (si-face attack)

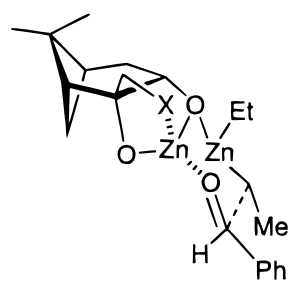

B, $X=$ OR or NRAr

(si-face attack)
Figure 3. Favorable transition states proposed for the asymmetric $\mathrm{LAH}$ reduction $(\mathbf{A})$ and $\mathrm{Et}_{2} \mathrm{Zn}$ addition (B).

The facial selectivities realized in the $\mathrm{LAH}$ reduction of aromatic methyl ketones using modifier $\mathbf{1 0 b}$ are superior to those utilizing simple terpenic diol modifiers (<30\% ee)..$^{8}$ Our results demonstrated the importance of the anilino substituent at C-10 in the modifier 10b, compared with the $\mathrm{N}$-methylanilino substituent of $\mathbf{1 1}$ or the benzyloxy substituent of $\mathbf{1 2}$, for the control of chirality in the enantioselective $\mathrm{LAH}$ reduction of ketones. The asymmetric induction was further improved by the ethoxy group at C-3 of modifier 10b, compared with the hydroxyl group of modifiers 5-9. A possible transition state for the stereochemical outcome, as exemplified by the reaction of acetophenone, is illustrated in Figure 3 (A). ${ }^{6}$ The chiral $\mathrm{LAH} / \mathbf{1 0 b}$ reagent is presumably formed by $\mathrm{O}-\mathrm{Al}-\mathrm{N}$ bondings and $\mathrm{O}-\mathrm{Li}-\mathrm{O}$ chelation. The ethoxy group at C-3 thus plays a role to differentiate two reaction faces of this chiral reducing agent. The incoming carbonyl group would coordinate with the $\mathrm{Li}^{+}$ion to form a chairlike transition state, in which the aryl group is equatorially oriented. Attack of hydride thus occurs at the si-face of acetophenone to furnish the observed $\mathrm{R}$ alcohol. The alternative transition state by placing the bulkier aryl group on the axial position is disfavored as it would exert repulsions against the anilino and ethoxy groups. Diols 5-9 are poor modifiers because their hydroxyl groups at C-2 and C-3 would compete in bonding with aluminum hydride and thus reduce the face selection.

$\mathbf{E t}_{\mathbf{2}} \mathbf{Z n}$ Addition. Unlike LAH reduction, modifiers 5-10 operated differently in the addition of diethylzinc onto benzaldehyde. The diol ligands 5-9 turned out to be better promoters than the alcohol ligand $\mathbf{1 0}$ for the asymmetric $\mathrm{Et}_{2} \mathrm{Zn}$ addition reactions. The addition reaction with benzal dehyde was generally carried out at room temperature by using 2.2 equiv of $\mathrm{Et}_{2} \mathrm{Zn}$ and $2 \mathrm{~mol} \%$ of a pinane-type promoter (Table 3 ). The reaction using al cohol ligands $\mathbf{1 0 a}-\mathbf{d}$ gave the product 1-phenyl propanol (19a) in favor of the R enantiomer (9-50\% ee), whereas that using diol ligands 5-9 gave predominantly the S enantiomer (up to $88 \%$ ee).

The chemical yields of $\mathrm{S}$ enriched alcohol 19a were in the range of $75-92 \%$, and the chiral ligands were recovered in good yields (ca. 94\%) from the reaction mixture by silica gel chromatography. The ee value of 19a was determined by HPLC on a Chiral cel OD column. In most cases, the reactions performed in hexane solution tended to show higher asymmetric induction than those performed in toluene. The $\mathrm{Et}_{2} \mathrm{Zn}$ addition reactions using either the ligand $\mathbf{8 e}$ or the diastereomer $\mathbf{8 f}$, prepared from (1R)-myrtenol with (S)- or (R)-1-phenylbutanol,

(8) (a) Haller, R.; Schneider, H. J . Chem. Ber. 1973, 106, 1312. (b) Lund, E. D.; Shaw, P. E. J . Org. Chem. 1977, 42, 2073.
Table 3. Chiral Ligand Promoted Reaction of Benzaldehyde with Diethylzinc, Giving Alcohol 19a ${ }^{a}$

\begin{tabular}{|c|c|c|c|c|}
\hline entry & ligand & yieldb/\% & $\mathrm{ee}^{\mathrm{b}} / \%$ & configb \\
\hline 1 & $10 a$ & $(60)^{c}$ & $(9)^{c}$ & $\mathrm{R}$ \\
\hline 2 & $10 b$ & $(73)^{c}$ & $(47)^{c}$ & $\mathrm{R}$ \\
\hline 3 & $10 c$ & $(68)^{c}$ & $(50)^{c}$ & $\mathrm{R}$ \\
\hline 4 & 10d & $(66)^{c}$ & $(46)^{c}$ & $\mathrm{R}$ \\
\hline 5 & $5 a$ & $85(81)^{c}$ & $82(62)^{c}$ & $\mathrm{~S}$ \\
\hline 6 & $5 b$ & $84(83)^{c}$ & $82(79)^{c}$ & $\mathrm{~S}$ \\
\hline 7 & $5 c$ & $83(81)^{c}$ & $88(79)^{c}$ & $\mathrm{~S}$ \\
\hline 8 & $5 d$ & $84(82)^{c}$ & $82(79)^{c}$ & S \\
\hline 9 & $6 a$ & $87(77)^{c}$ & $37(16)^{c}$ & $\mathrm{~S}$ \\
\hline 10 & $6 b$ & $81(80)^{c}$ & $77(69)^{c}$ & $\mathrm{~S}$ \\
\hline 11 & $6 c$ & $77(77)^{\mathrm{c}}$ & $69(62)^{c}$ & S \\
\hline 12 & 6d & $83(79)^{c}$ & $86(78)^{c}$ & S \\
\hline 13 & $6 e$ & $84(84)^{c}$ & $84(85)^{c}$ & $\mathrm{~S}$ \\
\hline 14 & $6 f$ & $79(75)^{\mathrm{c}}$ & $23(11)^{c}$ & $\mathrm{~S}$ \\
\hline 15 & 7b & $86(88)^{c}$ & $77(57)^{c}$ & S \\
\hline 16 & 7c & $87(83)^{c}$ & $81(72)^{c}$ & $\mathrm{~S}$ \\
\hline 17 & $7 d$ & $86(84)^{c}$ & $86(80)^{c}$ & S \\
\hline 18 & $7 e$ & $84(87)^{c}$ & $81(73)^{c}$ & $\mathrm{~S}$ \\
\hline 19 & $8 a$ & $88(88)^{c, d}$ & $76(74)^{c, d}$ & $\mathrm{~S}$ \\
\hline 20 & $8 b$ & $84(85)^{c}$ & $77(71)^{c}$ & $\mathrm{~S}$ \\
\hline 21 & $8 c$ & $81(88)^{c}$ & $70(79)^{c}$ & $\mathrm{~S}$ \\
\hline 22 & 8d & $84(85)^{c}$ & $79(78)^{c}$ & $\mathrm{~S}$ \\
\hline 23 & $8 e$ & $91(92)^{c, d}$ & $86(82)^{c, d}$ & S \\
\hline 24 & $8 f$ & $(68)^{\mathrm{e}}$ & $(70)^{\mathrm{e}}$ & S \\
\hline 25 & $9 a$ & $80(85)^{c}$ & $70(80)^{c}$ & $\mathrm{~S}$ \\
\hline 26 & $9 b$ & $85(90)^{c}$ & $84(84)^{c}$ & $\mathrm{~s}$ \\
\hline 27 & $9 c$ & $82(85)^{c}$ & $61(75)^{c}$ & $\mathrm{~S}$ \\
\hline 28 & 9d & $85(89)^{c}$ & $83(79)^{c}$ & $\mathrm{~S}$ \\
\hline
\end{tabular}

a The reaction was conducted in hexane solution at room temperature for $16 \mathrm{~h}$ with a molar ratio of $\mathrm{PhCHO} / \mathrm{Et}_{2} \mathrm{Zn} /$ ligand $=1.0: 2.2: 0.02$. ${ }^{\mathrm{b}}$ Refer to the footnote of Table 1 for isolated yields, ee values, and absolute configuration of major enantiomers. c The number in parentheses indicates the result of a similar reaction conducted in toluene solution. $d$ The yield and ee value of the alcohol product 19a decreased when the reaction was performed with 1.2 equiv of $\mathrm{Et}_{2} \mathrm{Zn}$ in toluene solution. Using $\mathbf{8 a}$ : $68 \%$ yield, $66 \%$ ee. Using 8 e: $72 \%$ yield, $75 \%$ ee. e The reaction was performed with 1.2 equiv of $E t_{2} Z n$ in toluene solution.

Table 4. Nonlinear Effect of Optically Enriched Ligand $8 e$ in the Reaction of Benzaldehyde with Diethylzinc, Giving Alcohol $19 a^{a}$

\begin{tabular}{ccccc}
\hline entry & ee/\% of $\mathbf{8 e}$ & yield/\% & ee/\% of 19a & config \\
\hline 1 & 14.1 & 88 & 33 & $\mathrm{~S}$ \\
2 & 23.5 & 87 & 41 & $\mathrm{~S}$ \\
3 & 37.6 & 89 & 54 & $\mathrm{~S}$ \\
4 & 47.0 & 88 & 67 & $\mathrm{~S}$ \\
5 & 70.5 & 88 & 77 & $\mathrm{~S}$ \\
6 & 93.8 & 91 & 82 & $\mathrm{~S}$
\end{tabular}

a Molar ratio $\mathrm{PhCHO} / \mathrm{Et}_{2} \mathrm{Zn} / \mathbf{8 e}=1.0: 2.2: 0.02$. The reaction was conducted in hexane solution, refer to Table 3 for detailed conditions.

occurred with the same enantiotopic face selection (compared entries 23 and 24 of Table 3). The enantioselectivity slightly decreased when the reaction was conducted with 1.2 equiv of $\mathrm{Et}_{2} \mathrm{Zn}$ (entries 19 and 23, Table 3). A nonlinear asymmetric effect was observed by using the chiral ligand $\mathbf{8 e}$ of different optical purities to promote the addition of $\mathrm{Et}_{2} \mathrm{Zn}$ with $\mathrm{PhCHO}$. The product (S)-19a was obtained in a higher optical yield by comparison with the optical purity of the starting ligand $\mathbf{8 e}$, when $\mathbf{8 e}$ had $70.5 \%$ or less enantiomeric excesses (entries $1-5$, Table 4).

Using diol ligands $\mathbf{5 c}$ or $\mathbf{8 e}$ as the chiral promoters, the addition reactions of $E t_{2} Z n$ to various substituted benzaldehydes also afforded the products $\mathbf{1 9 b}-\mathbf{h}$ in dominance of $\mathrm{S}$ enantiomers (Table 5). The ee values of $\mathbf{1 9 b}-\mathbf{h}$ were determined by HPLC analyses of their 
Table 5. Chiral Ligand Promoted Reaction of Substituted Benzaldehydes with Diethylzinca

\begin{tabular}{|c|c|c|c|c|c|c|}
\hline entry & aldehyde & ligand & product $^{b}$ & yield/\% & ee/\% & configc \\
\hline 1 & $\mathrm{o}-\mathrm{FC}_{6} \mathrm{H}_{4} \mathrm{CHO}$ & $5 c$ & $19 b$ & 80 & 75 & $\mathrm{~S}$ \\
\hline 2 & $\mathrm{o}-\mathrm{FC}_{6} \mathrm{H}_{4} \mathrm{CHO}$ & $8 e$ & $19 b$ & 80 & 78 & $\mathrm{~S}$ \\
\hline 3 & $\mathrm{p}-\mathrm{FC}_{6} \mathrm{H}_{4} \mathrm{CHO}$ & $5 c$ & $19 c$ & 81 & 80 & $\mathrm{~S}$ \\
\hline 5 & $\mathrm{~m}-\mathrm{ClC}_{6} \mathrm{H}_{4} \mathrm{CHO}$ & $5 c$ & 19d & 89 & 79 & $\mathrm{~S}$ \\
\hline 6 & $\mathrm{~m}-\mathrm{ClC}_{6} \mathrm{H}_{4} \mathrm{CHO}$ & $8 e$ & 19d & 84 & 71 & $\mathrm{~S}$ \\
\hline 7 & $\mathrm{p}-\mathrm{ClC}_{6} \mathrm{H}_{4} \mathrm{CHO}$ & $5 c$ & $19 e$ & 84 & 84 & S \\
\hline 8 & $\mathrm{p}-\mathrm{ClC}_{6} \mathrm{H}_{4} \mathrm{CHO}$ & $8 e$ & $19 e$ & 81 & 82 & S \\
\hline 9 & $\mathrm{~m}-\mathrm{BrC}_{6} \mathrm{H}_{4} \mathrm{CHO}$ & $5 c$ & $19 f$ & 80 & 79 & \\
\hline 10 & $\mathrm{~m}-\mathrm{BrC}_{6} \mathrm{H}_{4} \mathrm{CHO}$ & $5 c$ & $19 f$ & 86 & 72 & \\
\hline 11 & $\mathrm{p}-\mathrm{BrC}_{6} \mathrm{H}_{4} \mathrm{CHO}$ & $5 c$ & $19 g$ & 80 & 65 & $\mathrm{~S}$ \\
\hline 12 & $\mathrm{p}-\mathrm{BrC}_{6} \mathrm{H}_{4} \mathrm{CHO}$ & $8 e$ & $19 g$ & 78 & 55 & $\mathrm{~S}$ \\
\hline 13 & $\mathrm{p}-\mathrm{MeC}_{6} \mathrm{H}_{4} \mathrm{CHO}$ & $5 c$ & $19 \mathrm{~h}$ & 87 & 67 & $\mathrm{~S}$ \\
\hline 14 & p-MeC ${ }_{6} \mathrm{H}_{4} \mathrm{CHO}$ & $8 e$ & 19h & 86 & 54 & $\mathrm{~S}$ \\
\hline
\end{tabular}

a The reaction was conducted in hexane solution with a molar ratio of aldehyde/ $\mathrm{t}_{2} \mathrm{Zn} / \mathrm{ligand}=1.0: 2.2: 0.02$. Refer to Table 3 for detailed conditions. $\mathrm{b}$ The alcohol products or their 3,5-dinitrobenzoate derivatives were analyzed by HPLC on a Chiralcel OD column to determine the ee values. c Configuration of the major enantiomer was assigned according to the measurement of optical rotation.

corresponding 3,5-dinitrobenzoate derivatives on a Chiralcel OD column.

As the addition reaction showed a nonlinear asymmetric effect, it may involve a quite complicated mechanism. ${ }^{3,9}$ To explain why the diol ligands 5-9 are better promoters than the al cohol ligands $\mathbf{1 0}$ for the formation of 19a with higher chemical yields and ee values, one can assume that a diol ligand favors to react with $\mathrm{Et}_{2} \mathrm{Zn}$ to form a cyclic dialkoxyzinc intermediate. ${ }^{9}$ The zinc ion in this intermediate is also chelated with the anilino or alkoxy group at C-10 (Figure 3, B). By analogy to previously proposed intermediates 3,9 for diol ligandpromoted $\mathrm{Et}_{2} \mathrm{Zn}$ addition reactions, a transition state illustrated in $\mathbf{B}$ is a reasonable working hypothesis. It involves a chairlike form with the participation of two $\mathrm{Et}_{2} \mathrm{Zn}$ molecules. The bulkier phenyl group would take the energetically favorable equatorial position and transfer of an ethyl group occurs at the si-face of PhCHO to furnish the observed (S)-alcohol. Several other possible intermediates were excluded for steric reasons according to examination of their molecular models.

\section{Conclusion}

We have demonstrated that asymmetric $\mathrm{LAH}$ reduction of ketones and $\mathrm{Et}_{2} \mathrm{Zn}$ addition to aldehydes are effectively promoted by pinane-type tridentate ligands. These two methods are complementary in the prepara-

(9) Discussion of reaction mechanism: (a) Kitamura, M.; Suga, S.; Oka, H.; Noyori, R. J . Am. Chem. Soc. 1998, 120, 9800. (b) Goldfuss, B.; Houk, K. N. J . Org. Chem. 1998, 63, 8998. (c) Seebach, D.; Plattner, D. A.; Beck, A. K.; Wang, Y. M.; Hunziker, D. Helv. Chim. Acta 1992, 75, 2171. (d) Nowotny, S.; Vettel, S.; Knochel, P. Tetrahedron Lett. 1994, 35, 4539. (e) Bolm, C.; Mueller, J . Tetrahedron 1994, 50, 4355 (f) Rijnberg, E.; Hovestad, N. J .; Kleij, A. W.; J astrzebski, J . T. B. H.; Boersma, J.; J assen, M. D.; Spek, A. L.; van K oten, G. Organometallics 1997, 16, 2847. (g) Kotsulei, H.; Wakao, M.; Hayakawa, H.; Shimanouchi, T.; Shiro, M. J. Org. Chem. 1996, 61, 8915. Examples of asymmetric $\mathrm{Et}_{2} \mathrm{Zn}$ additions using diol promoters: (h) Bolm, C. Zehnder, M.; Bur, D. Angew. Chem., Int. Ed. Engl. 1990, 29, 205. (i) Rosini, C.; Franzini, L.; Pini, D.; Salvadori, P. Tetrahedron: Asymmetry 1990, 1, 587. (j) Prasad, K. R. K.; oshi, N. N. Tetrahedron: Asymmetry 1996, 7, 1957. (k) Kitajima, H.; I to, K., Katsuki, T. Chem. Lett. 1996, 343. Examples of asymmetric $\mathrm{Et}_{2} \mathrm{Zn}$ additions using terpenic amino alcohol promoters: (I) Masui, M.; Shioiri, T. Synlett 1997, 273. (m) Goralski, C. T.; Chrisman, W.; Hasha, D. L.; Nicholson, L. W.; Rudolf P. R.; Zakett, D.; Singaram, B. Tetrahedron: Asymmetry 1997, 8, 3863. (n) Genov, M.; Dimitrov, V.; I vanova, V. Tetrahedron: Asymmetry 1997, 8, 3703. tion of optically active secondary alcohols. Formation of $(\mathrm{R})$-alcohols is favored in the LAH reduction, whereas formation of (S)-alcohols is favored in the $\mathrm{Et}_{2} \mathrm{Zn}$ addition. The diol ligands 5-9 are efficient promoters for asymmetric $\mathrm{Et}_{2} \mathrm{Zn}$ additions, whereas the alcohol $\mathbf{1 0 b}$ is the best modifier for $\mathrm{LAH}$ reductions according to our current results. We have also found that asymmetric $\mathrm{Et}_{2} \mathrm{Zn}$ addition promoted by alcohols $\mathbf{1 0}$ showed an enantiotopic preference opposite to those reactions using diol promoters 5-9. The designed compounds 5-10 may not be ideal modifiers by comparison with those reagents showing extremely high enantioselectivity in the similar reactions. ${ }^{2,3}$ However, the present methods are still practical as the pinane-type reagents are easily prepared, and these chiral modifiers are recovered from the reaction mixture in nearly quantitative yields.

\section{Experimental Section}

All reactions were carried out under nitrogen atmosphere except as otherwise noted. Mel ting points are uncor rected. ${ }^{1} \mathrm{H}$ NMR spectra were recorded at 200,300 , or $400 \mathrm{MHz} ;{ }^{13} \mathrm{C}$ NMR spectra were recorded at 50,75 , or $100 \mathrm{MHz}$. Chloroform $(\delta=$ 7.24 ppm) was used as internal standard in ${ }^{1} \mathrm{H}$ NMR spectra. Mass spectra were recorded at an ionizing voltage of 70 or 20 eV. Merck silica gel 60F sheets were used for analytical thinlayer chromatography. Column chromatography was performed on $\mathrm{SiO}_{2}$ (70-230 mesh); gradients of EtOAc and n-hexane were used as eluents. Enantiomeric excess was determined by HPLC using a Chiralcel OD column $(0.46 \mathrm{~cm}$ i.d. $\times 25 \mathrm{~cm}$ ). The optical rotations were measured in $\mathrm{CHCl}_{3}$ solution on a digital polarimeter with a cuvette of $1 \mathrm{~cm}$ length.

General Procedure for the Preparation of C-10 Substituted $\alpha$-Pinanediols 5-9. To a stirred suspension of $\mathrm{KH}$ $(24 \mathrm{mmol})$ in dry THF $(20 \mathrm{~mL})$ was added dropwise the nucleophile (12 mmol, aniline or alcohol) via a syringe, and the reaction was stirred at room temperature for 30 min after the completion of the addition. A solution of myrtenyl bromide (12 mmol) dissolved in THF (10 mL) was then added slowly. The reaction was stirred at room temperature for 3-6 h. The reaction was quenched by addition of $\mathrm{H}_{2} \mathrm{O}(2 \mathrm{~mL})$. THF was removed under reduced pressure, and the residue was extracted with EtOAc. The organic layer was washed with brine, dried $\left(\mathrm{MgSO}_{4}\right)$, filtered, and concentrated. The crude product was purified by flash column chromatography (EtOAc/hexane $=1: 20$ ) to give the $\mathrm{C}-10$ substituted $\alpha$-pinenes 3 and 4 (65$85 \%$ chemical yields).

To a stirred solution of the $\alpha$-pinene derivative ( $\mathbf{3}$ or $\mathbf{4}, 10$ $\mathrm{mmol})$ in THF (28 $\mathrm{mL}) /$ water $(3 \mathrm{~mL}) /$ acetone $(10 \mathrm{~mL})$ was added trimethylamine $\mathrm{N}$-oxide ( $12 \mathrm{mmol})$ at room temperature. A $1 \% \mathrm{w} / \mathrm{w} \mathrm{OsO}_{4}-\mathrm{THF}$ solution ( $8 \mathrm{~mL}, 3 \mathrm{~mol} \%$ ) was added, and the mixture was refluxed. The reaction was monitored by TLC until no starting material could be detected (ca. 4 days). The reaction mixture was quenched by addition of saturated $\mathrm{NaHSO}_{3}$ solution $(20 \mathrm{~mL})$. The sol vent was removed by rotary evaporation. The aqueous layer was extracted with EtOAc. The combined organic layer was washed with brine, dried $\left(\mathrm{MgSO}_{4}\right)$, filtered, and concentrated. The crude product was purified by flash column chromatography (silica gel, EtOAc/hexane $=1: 10$ ) to furnish the desired C-10-substituted $\alpha$-pinanediols 5-9 (50$81 \%$ chemical yields).

General Procedure for the Preparation of C-3 AlkoxySubstituted $\alpha$-Pinanols 10-12. To a stirred suspension of $\mathrm{NaH}(3 \mathrm{mmol})$ in dry THF $(20 \mathrm{~mL})$ was added a THF solution (5 mL) of the diol 5-9 (1 mmol). After $30 \mathrm{~min}$, a solution of alkyl bromide ( $1.1 \mathrm{mmol})$ in THF $(3 \mathrm{~mL})$ was added via a syringe, and the mixture was stirred at room temperature for $24 \mathrm{~h}$. The reaction was quenched by addition of $\mathrm{H}_{2} \mathrm{O}(1 \mathrm{~mL})$. THF was removed under reduced pressure, and the residue was extracted with EtOAc. The organic layer was washed with brine, dried $\left(\mathrm{MgSO}_{4}\right)$, filtered, and concentrated. The crude product was purified by flash col umn chromatography (silica 
gel) with elution of hexane/EtOAc to give the corresponding C-3 alkoxy-substituted $\alpha$-pinanol products 10-12 (76-92\% chemical yields).

General Procedure for the LAH Reduction of Methyl Ketones (Tables 1 and 2). A stock solution of lithium aluminum hydride $\left(0.6 \mathrm{~mL}\right.$ of $1 \mathrm{M}$ solution in $\left.\mathrm{Et}_{2} \mathrm{O}\right)$ was placed in a $10 \mathrm{~mL}$ round-bottomed flask. An appropriate chiral modifier (10a-e, $0.66 \mathrm{mmol}, 1.1$ equiv) in THF solution ( $3 \mathrm{~mL}$ ) was added dropwise at room temperature, and evolution of hydrogen was apparent. The mixture was stirred at room temperature for $1 \mathrm{~h}$ and cooled to $-78^{\circ} \mathrm{C}$, and a solution of methyl ketone $(0.3 \mathrm{mmol}, 0.5$ equiv) in THF ( $3 \mathrm{~mL})$ was added dropwise. The reaction was complete in $1 \mathrm{~h}$ as shown by TLC analysis. A solution of dilute aqueous $\mathrm{HCl}(5 \%)$ solution $(3 \mathrm{~mL})$ was added slowly, and the mixture was warmed to room temperature and stirred for $4 \mathrm{~h}$. After removal of THF by rotary evaporation, the mixture was extracted with EtOAc. The organic phase was washed with brine, dried $\left(\mathrm{MgSO}_{4}\right)$, filtered, and concentrated. The residue was chromatographed on a silica gel column by elution with gradients of EtOAd hexane to give the desired al cohol products $\mathbf{1 4 a}-\mathbf{1 8}(83-96 \%$ chemical yields) and the modifier $10 \mathbf{a}-\mathbf{e}(90-96 \%$ recovery). The ee values of the alcohol products were determined by HPLC on a Chiralcel OD column (2-propanol/hexane elution). The absolute configuration of major enantiomers was assigned by comparison of the optical rotations with the reported values.

General Procedure for the Addition of Diethylzinic to Aldehydes (Tables 3-5). The chiral catalyst (5-10, 0.038 $\mathrm{mmol}, 0.02$ equiv) was dissolved in hexane $(10 \mathrm{~mL})$ and $\mathrm{Et}_{2} \mathrm{Zn}$ (4.2 mmol, 2.2 equiv, $1 \mathrm{M}$ standard solution in hexane) was injected. An appropriate aldehyde ( $1.9 \mathrm{mmol}, 1$ equiv) was added dropwise via a syringe, and the mixture was stirred for $16 \mathrm{~h}$. The mixture was quenched by addition of $5 \% \mathrm{HCl}(3 \mathrm{~mL})$. The hexane layer was separated and subsequently washed with brine. After drying over $\mathrm{MgSO}_{4}$ and filtration, the hexane was removed under reduced pressure, and the crude alcohol products 19-22 (60-92\% chemical yields) were purified by flash column chromatography (hexane/EtOAc). The chiral catal yst was recovered in $92-96 \%$ yiel ds. The ee values of the alcohol products were determined by HPLC on a Chiralcel OD column (2-propanol/hexane elution). The absolute configuration of the major enantiomer was assigned by comparison of the optical rotation with the reported value.

(1R,2S,3S,5R )-(+)-6,6-Dimethyl-2-(N-butylanilino)methylbicyclo[3.1.1]heptane-2,3-diol (5c): solid; $\mathrm{mp} 80-$ $81^{\circ} \mathrm{C} ;[\alpha]^{25} \mathrm{D}=+11.1\left(\mathrm{C}=0.94, \mathrm{CHCl}_{3}\right)$; IR $\left(\mathrm{CHCl}_{3}\right) 3520(\mathrm{OH})$, 1605, $1054 \mathrm{~cm}^{-1}$; ${ }^{1} \mathrm{H}$ NMR $\left(300 \mathrm{MHz} \mathrm{CDCl}_{3}\right) \delta 7.24$ (dd, J= 8.0, 7.8 Hz, $2 \mathrm{H}), 6.92(\mathrm{~d}, \mathrm{~J}=8.0 \mathrm{~Hz}, 2 \mathrm{H}), 6.79(\mathrm{t}, \mathrm{J}=7.8 \mathrm{~Hz}$, $1 \mathrm{H}), 4.09(\mathrm{dd}, \mathrm{J}=9.3,5.7 \mathrm{~Hz}, 1 \mathrm{H}), 3.48(\mathrm{~d}, \mathrm{~J}=15.0 \mathrm{~Hz}, 1$ $\mathrm{H}), 3.33(\mathrm{t}, \mathrm{J}=7.8 \mathrm{~Hz}, 2 \mathrm{H}), 3.30(\mathrm{~d}, \mathrm{~J}=15.0 \mathrm{~Hz}, 1 \mathrm{H}), 2.53-$ $2.43(\mathrm{~m}, 1 \mathrm{H}), 2.24-2.16(\mathrm{~m}, 1 \mathrm{H}), 2.15(\mathrm{t}, \mathrm{J}=6.0 \mathrm{~Hz}, 1 \mathrm{H})$, $1.97-1.91(\mathrm{~m}, 1 \mathrm{H}), 1.70$ (ddd, J $=13.8,5.4,2.4 \mathrm{~Hz}, 1 \mathrm{H}), 1.58-$ $1.26(\mathrm{~m}, 4 \mathrm{H}) 1.47(\mathrm{~d}, \mathrm{~J}=9.6 \mathrm{~Hz}, 1 \mathrm{H}), 1.28(\mathrm{~s}, 3 \mathrm{H}), 1.04(\mathrm{~s}$, $3 \mathrm{H}), 0.93(\mathrm{t}, \mathrm{J}=7.2 \mathrm{~Hz}, 3 \mathrm{H}) ;{ }^{13} \mathrm{C} \mathrm{NMR}\left(75 \mathrm{MHz} \mathrm{CDCl}_{3}\right) \delta$ $149.89,129.18$ (2 C), 118.41, 115.46 (2 C), 76.00, 67.64, 61.33, $53.43,51.43,40.55,38.82,38.00,28.03,27.74,27.67,24.28$, 20.21, 13.86; MS m/z (rel intensity) $317\left(13, M^{+}\right), 162$ (100), 149 (9); HRMS calcd for $\mathrm{C}_{20} \mathrm{H}_{31} \mathrm{NO}_{2} 317.2355$, found 317.2353.

(1R,1'R,2S,3S,5R)-(+)-6,6-Dimethyl-2-(1-phenylbutoxy)methylbicyclo[3.1.1] heptane-2,3-diol (8e): solid; $\mathrm{mp} 62-$ $63{ }^{\circ} \mathrm{C} ;[\alpha]^{25} \mathrm{D}=+61.6\left(\mathrm{C}=0.7, \mathrm{CHCl}_{3}\right)$; IR $\left(\mathrm{CHCl}_{3}\right) 3570,1180$ $\mathrm{cm}^{-1} ;{ }^{1} \mathrm{H}$ NMR $\left(300 \mathrm{MHz} \mathrm{CDCl}_{3}\right) \delta 7.40-7.23(\mathrm{~m}, 5 \mathrm{H}), 4.24$ $(\mathrm{dd}, \mathrm{J}=7.8,5.7 \mathrm{~Hz}, 1 \mathrm{H}), 4.04(\mathrm{dt}, \mathrm{J}=9.3,5.7 \mathrm{~Hz}, 1 \mathrm{H}), 3.39$ $(\mathrm{s}, 1 \mathrm{H}, \mathrm{OH}), 3.29(\mathrm{~d}, \mathrm{~J}=9.3 \mathrm{~Hz}, 1 \mathrm{H}), 3.25(\mathrm{~d}, \mathrm{~J}=9.3 \mathrm{~Hz}, 1$ $\mathrm{H}), 3.02(\mathrm{~d}, \mathrm{~J}=3.8 \mathrm{~Hz}, 1 \mathrm{H}, \mathrm{OH}), 2.44-2.36(\mathrm{~m}, 1 \mathrm{H}), 2.21-$ $2.16(\mathrm{~m}, 1 \mathrm{H}), 2.10(\mathrm{t}, \mathrm{J}=6.0 \mathrm{~Hz}, 1 \mathrm{H}), 1.91-1.76(\mathrm{~m}, 2 \mathrm{H})$, $1.71-1.56(\mathrm{~m}, 2 \mathrm{H}), 1.48(\mathrm{~d}, \mathrm{~J}=9.9 \mathrm{~Hz}, 1 \mathrm{H}), 1.43-1.27(\mathrm{~m}, 2$
$\mathrm{H}), 1.19(\mathrm{~s}, 3 \mathrm{H}), 0.89(\mathrm{t}, \mathrm{J}=7.2 \mathrm{~Hz}, 3 \mathrm{H}), 0.71(\mathrm{~s}, 3 \mathrm{H}) ;{ }^{13} \mathrm{C}$ NMR $\left(75 \mathrm{MHz}_{2} \mathrm{CDCl}_{3}\right) \delta 142.24,128.43(2 \mathrm{C}), 127.65,126.66$ (2 C), 82.79, 78.25, 75.14, 66.09, 48.95, 40.56, 40.28, 38.65, 37.10, 27.77, 27.74, 23.83, 17.10, 13.90; MS m/z (rel intensity) $318\left(1, \mathrm{M}^{+}\right), 155(72)$; HRMS calcd for $\mathrm{C}_{20} \mathrm{H}_{30} \mathrm{O}_{3} 318.2195$, found 318.2198.

(1R,2S,3S,5R )-(-)-2-Anilinomethyl-6,6-di methyl-3ethoxybicyclo[3.1.1] heptan-2-ol (10b): oil; $[\alpha]^{25} \mathrm{D}=+11.5$ (c = 1.0, $\left.\mathrm{CHCl}_{3}\right)$; IR $\left(\mathrm{CHCl}_{3}\right) 3520,1610 \mathrm{~cm}^{-1} ;{ }^{1} \mathrm{H} \mathrm{NMR}(300$ $\left.\mathrm{MHz} \mathrm{CDCl}_{3}\right) \delta 7.16(\mathrm{t}, \mathrm{J}=8.0 \mathrm{~Hz}, 2 \mathrm{H}), 6.67(\mathrm{t}, \mathrm{J}=8.0 \mathrm{~Hz}$, $1 \mathrm{H}), 6.59(\mathrm{~d}, \mathrm{~J}=8.0 \mathrm{~Hz}, 2 \mathrm{H}), 4.24(\mathrm{br} \mathrm{s}, 1 \mathrm{H}, \mathrm{NH}), 4.15(\mathrm{~s}, 1$ $\mathrm{H}, \mathrm{OH}), 3.74-3.66(\mathrm{~m}, 2 \mathrm{H}), 3.52-3.46(\mathrm{~m}, 1 \mathrm{H}), 3.17(\mathrm{~d}, \mathrm{~J}=$ $11.7 \mathrm{~Hz}, 1 \mathrm{H}), 3.08(\mathrm{~d}, \mathrm{~J}=11.7 \mathrm{~Hz}, 1 \mathrm{H}), 2.43-2.38(\mathrm{~m}, 1 \mathrm{H})$, 2.26-2.17 (m, 2 H), 1.97-1.78 (m, $1 \mathrm{H}), 1.75$ (ddd, J = 13.8, 5.1, 2.7 Hz, $1 \mathrm{H}), 1.47(\mathrm{~d}, \mathrm{~J}=9.9 \mathrm{~Hz}, 1 \mathrm{H}), 1.26(\mathrm{~s}, 3 \mathrm{H}), 1.22$ $(\mathrm{t}, \mathrm{J}=3.6 \mathrm{~Hz}, 3 \mathrm{H}), 0.98(\mathrm{~s}, 3 \mathrm{H}) ;{ }^{13} \mathrm{C} \mathrm{NMR}\left(75 \mathrm{MHz}^{\mathrm{C}} \mathrm{CDCl}_{3}\right)$ $\delta 149.11,129.26(2 \mathrm{C}), 117.06,112.93$ (2 C) $, 75.23,73.92,65.31$, 53.49, 49.43, 40.42, 38.29, 35.40, 27.64, 27.56, 24.16, 15.54; MS m/z (rel intensity) $289\left(15, \mathrm{M}^{+}\right), 106$ (100); HRMS calcd for $\mathrm{C}_{18} \mathrm{H}_{27} \mathrm{NO}_{2}$ 289.2042, found 289.2036.

N-[6,6-Dimethyl-3-ethoxy-2-hydroxybicyclo[3.1.1]hept10-yl]-N-phenyl-3,5-dinitrobenzamide (13): H PLC (Chiralcel OD, 2-propanol/hexane (2:1), $1 \mathrm{~mL} / \mathrm{min}) t_{R} 31.5 \mathrm{~min}$ [(1R,2S,3S,5R)-isomer], $42.3 \mathrm{~min}$ [(1S,2R,3R,5S)-isomer].

1-(1-Cyclohexenyl)ethanol (18): $:^{19}[\alpha]^{25} \mathrm{D}=+7.4(\mathrm{c}=2.6$, $\mathrm{CHCl}_{3}$ ) (74\% ee favoring the $\mathrm{R}$ enantiomer) (lit. ${ }^{19}[\alpha]^{25} \mathrm{D}+3.29$ $\left(\mathrm{c}=2.49, \mathrm{CHCl}_{3}\right)$ ); $\mathrm{HPLC}$ for the 3,5-nitrobenzoate derivative (Chiral cel OD, 2-propanol/hexane (1:40), $0.41 \mathrm{~mL} / \mathrm{min}$ ) $t_{R} 42.2$ min (S-enantiomer), 46.6 min (R-enantiomer).

1-(2-Fluorophenyl)propanol (19b): $:^{21}[\alpha]^{25} \mathrm{D}=-22.4(\mathrm{c}=$ 2.0, $\left.\mathrm{CHCl}_{3}\right)\left(75 \%\right.$ ee favoring the S-enantiomer) (lit. ${ }^{21}[\alpha]^{25} \mathrm{D}$ -20.06 ( $\mathrm{c}=1.77, \mathrm{CHCl}_{3}, 62 \%$ ee favoring the $\mathrm{S}$ enantiomer); HPLC for the 3,5-nitrobenzoate derivative (Chiralcel OD, 2-propanol/hexane (1:5), $0.48 \mathrm{~mL} / \mathrm{min}$ ) $t_{R} 36.4 \mathrm{~min}$ ( $R$ enantiomer), $43.4 \mathrm{~min}$ (S enantiomer).

Acknowledgment. We thank the National Science Council of the Republic of China for financial support.

Supporting Information Available: Additional physical and spectral data of new compounds. This material is available free of charge via the Internet at http://pubs.acs.org.

J O982403B

(10) (a) Davies, S. G.; Goodfellow, C. L. J . Chem. Soc., Perkin Trans. 1 1990, 393. (b) Takemura, T.; Saito, K.; Nakazawa, S.; Mori, N. Tetrahedron Lett. 1992, 33, 6335.

(11) Nakamura, K.; Kawasaki, M.; Ohno, A. Bull. Chem. Soc. J pn. 1996, 69, 1079

(12) Resnick, S. M.; Torok, D. S.; Gibson, D. T. J . Org. Chem. 1995 60. 3546 .

(13) Kaufman, T. S. Tetrahedron Lett. 1996, 37, 5329.

(14) Corrie, J. E. T.; Reid, G. P.; Trenthan, D. R.; Hursthouse, M. B.; Mazid, M. A. J . Chem. Soc., Perkin Trans. 1 1992, 1015.

(15) Ziffer, H.; Kawai, K.; Kasai, M.; I muta, M.; Forussios, C. J . Org. Chem. 1983, 48, 3017

(16) (a) Naemura, K.; Murata, M.; Tanaka, R.; Yano, M.; Hirose K.; Tobe, Y. Tetrahedron: Asymmetry 1996, 7, 3285. (b) Collyen, K. J . Chem. Soc, 1940, 7, 676.

(17) Fantin, G.; Fogagnolo, M.; Medici, A.; Pedrini, P.; Poli, S. Gardini, F. Tetrahedron: Asymmetry 1993, 4, 1607. (b) Bradshaw, C. W.; Hummel, W.: Wong, C.-H. J . Org. Chem. 1992, 57, 1532.

(18) Srary, I.; Zajicek, J .; Kocovsky, P. Tetrahedron 1992, 48, 7229.

(19) Gao, Y.; Hanson, R. M.; Klunder, J . M.; Ko, S. Y.; Masamune, H.; Sharpless, K. B. J . Am. Chem. Soc. 1987, 109, 5765.

(20) Kang, J .; Lee, J . W.; Kim, J . I. J . Chem. Soc., Chem. Commun. 1994, 2009 .

(21) Seebach, D.; Beck, A. K.; Schmidt, B.; Wang, Y. M. Tetrahedron 1994, 50, 4363.

(22) Chaloner, P. A.; Langadianou, E.; Perera, S. A. R. J . Chem. Soc., Perkin Trans. 1 1991, 2731. 